Received: 12 May 2019

Accepted: 12 August 2019

Published online: 29 August 2019

\section{Evaluation of toll-like receptors as prognostic biomarkers in gastric cancer: high tissue TLR5 predicts a better outcome}

\begin{abstract}
Aaro Kasurinen $\mathbb{1}^{1}{ }^{1}$, Jaana Hagström ${ }^{2}$, Alli Laitinen ${ }^{1,3}$, Arto Kokkola ${ }^{3}$, Camilla Böckelman ${ }^{1,3}$ \& Caj Haglund ${ }^{1,3}$

Toll-like receptors (TLRs), key proteins in innate immunity, appear to contribute to the inflammatory environment in carcinogenesis. Thus, we aimed to evaluate the tissue expressions of TLR1, TLR2, TLR4, TLR5, TLR7, and TLR9 as potential prognostic biomarkers in gastric cancer. We applied immunohistochemistry to study tissue samples from 313 patients operated on for gastric adenocarcinoma between 2000 and 2009 at the Department of Surgery, Helsinki University Hospital, Finland. A high expression of each TLR studied associated with the high expression of each other and with the intestinal-type histology ( $p<0.001$ for all). Five-year disease-specific survival among patients with a high TLR5 was $53.4 \%$ (95\% confidence interval $[\mathrm{CI}]$ 43.4-63.4), whereas among patients with a low TLR5 it was $37.6 \%(95 \% \mathrm{Cl} 30.0-45.2 ; \mathrm{p}=0.014)$. A high TLR5 expression functioned as a marker of a better prognosis, particularly among those with a stage II disease (hazard ratio [HR] 0.33; 0.13-0.83; $\mathrm{p}=0.019$ ) or an intestinal-type cancer (HR $0.58 ; 95 \% \mathrm{Cl} 0.34-0.98 ; \mathrm{p}=0.043$ ). In this study we show, for the first time, that a high TLR5 tissue expression may identify gastric cancer patients with a better prognosis, particularly among those with a stage II disease or an intestinal-type cancer.
\end{abstract}

Gastrointestinal tract malignancies cause more cancer-related deaths worldwide than any other form of cancer, accounting for more than $20 \%$ of all cancer-related fatalities ${ }^{1}$. Late diagnosis, often occurring already at an advanced disease stage, and a high recurrence risk result in poor prognoses.

Chronic inflammation contributes to carcinogenesis in the gastrointestinal tract, and several biomarkers have been studied in attempts to further clarify the pathology behind inflammation-associated cancers, including the toll-like receptors (TLRs) ${ }^{2-4}$. TLRs, a family of transmembranous pattern recognition receptors, play a crucial role in innate immunity. These receptors are expressed on antigen-presenting cells in the first line of defence, such as on the macrophages and dendritic cells, and activated by pathogen-associated molecular patterns ${ }^{5}$. In cancer, TLRs contribute to the inflammatory environment via activation by damage-associated molecular patterns ${ }^{6}$. However, TLRs may assume a heterogeneous role in cancer biology, since they appear to both induce antitumour factors and in different contexts promote procancerous mechanisms ${ }^{7}$. A sequence of increasing TLR2, TLR4, and TLR5 expression levels was observed with progression from normal gastric mucosa to pre-cancerous lesions, gastric dysplasia, and ultimately to gastric adenocarcinoma ${ }^{8}$. The highest TLR expression levels were found in dysplastic lesions, suggesting that TLRs may play a specific role in gastric cancer development.

TLR4 represents the most widely studied TLR in gastric cancer, and its polymorphism may associate with an increased risk of gastric cancer ${ }^{9,10}$. Furthermore, TLR4 signalling activation in gastric cancer cells by lipopolysaccharides increase the risk of metastasis ${ }^{11}$. In a study among 106 gastric adenocarcinoma patients, TLR3, TLR4, and TLR9 were highly expressed in gastric cancer tissues and survival worsened among patients with a high TLR3 expression $^{12}$. Moreover, TLR2 expression in gastric cancer has been linked to metastatic disease and increased invasion $^{13}$. In addition, TLR5 activation by flagellin, the major structural protein in bacterial flagellum, increases

\footnotetext{
${ }^{1}$ Translational Cancer Medicine Research Programme, University of Helsinki, Helsinki, Finland. ${ }^{2}$ Department of Pathology and Oral Pathology, University of Helsinki and Helsinki University Hospital, Helsinki, Finland. ${ }^{3}$ Department of Surgery, University of Helsinki and Helsinki University Hospital, Helsinki, Finland. Camilla Böckelman and Caj Haglund contributed equally. Correspondence and requests for materials should be addressed to Aaro Kasurinen (email: aaro.kasurinen@helsinki.fi)
} 

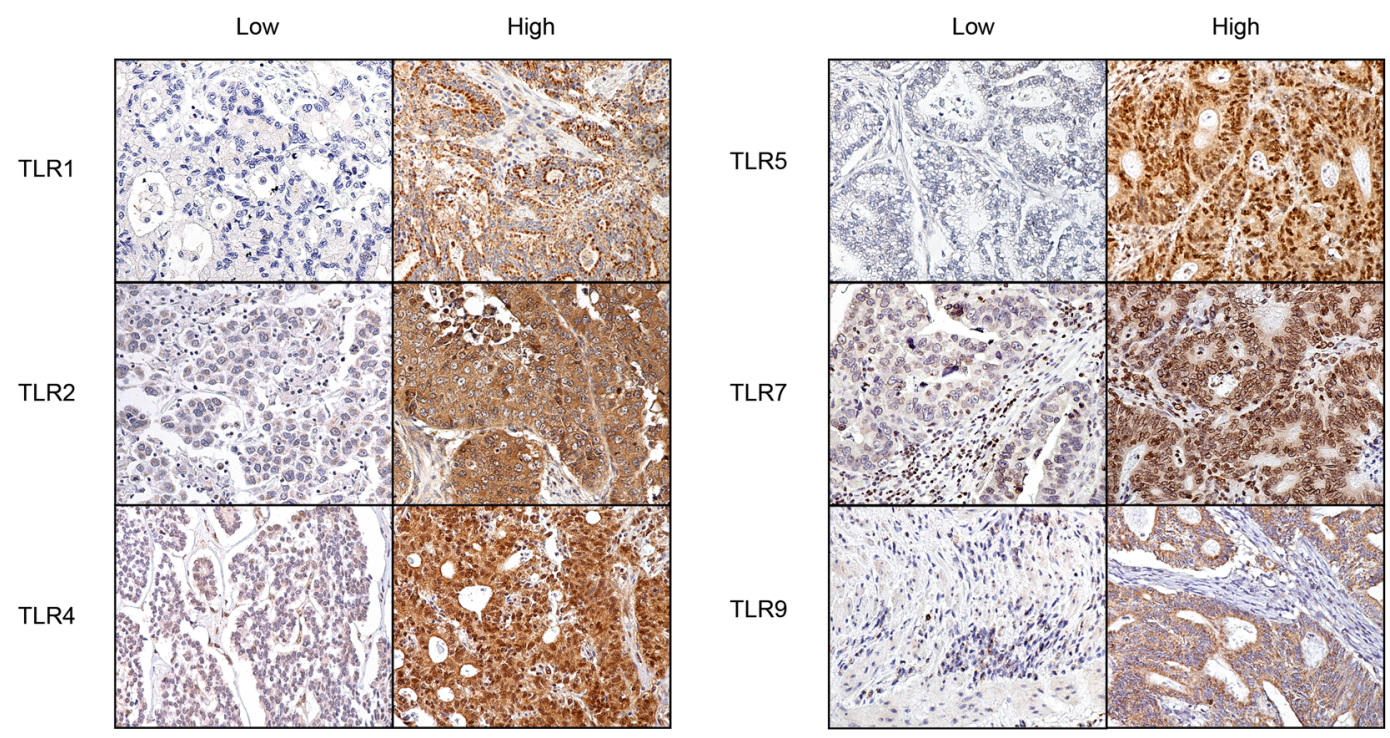

Figure 1. Representative images of immunohistochemistry demonstrating gastric cancer tumours with low versus high TLR immunoreactivities. Original magnification was $20 \times$.

\begin{tabular}{|l|l|l|c|l|l|}
\hline \multirow{2}{*}{} & \multicolumn{5}{l}{ Immunoreactivity } \\
\cline { 2 - 6 } & Strong (\%) & Moderate (\%) & Weak (\%) & Absent (\%) & Total \\
\hline TLR1 & $29(10.3)$ & $115(40.8)$ & $120(42.6)$ & $18(6.4)$ & 282 \\
\hline TLR2 & $44(16.0)$ & $122(44.4)$ & $90(32.7)$ & $19(6.9)$ & 275 \\
\hline TLR4 & $74(26.3)$ & $106(37.7)$ & $77(27.4)$ & $24(8.5)$ & 281 \\
\hline TLR5 & $11(4.0)$ & $98(35.4)$ & $114(41.2)$ & $54(19.5)$ & 277 \\
\hline TLR7 & $30(11.2)$ & $95(35.4)$ & $108(40.3)$ & $35(13.1)$ & 268 \\
\hline TLR9 & $13(4.7)$ & $130(46.9)$ & $115(41.5)$ & $19(6.9)$ & 277 \\
\hline
\end{tabular}

Table 1. Distribution of immunoreactivity for TLR1, TLR2, TLR4, TLR5, TLR7, and TLR9. Abbreviations: $\mathrm{TLR}=$ Toll-like receptor.

the proliferation of gastric cancer cells ${ }^{14}$. Subsequent TLR5 antagonism appeared to cancel the effect, suggesting that TLR5 signalling clearly contributes to the proliferation of gastric cancer cells. Yet, administering imiquimod (a TLR7 agonist) to gastric cancer cells results in a reduced proliferation ${ }^{15}$. In that study, TLR7 expression was low in gastric cancer cells compared to levels in adjacent healthy tissue. Genetic variations of TLR1 combined with an Helicobacter Pylori (H. pylori) infection predispose an individual to develop gastric cancer ${ }^{16}$. However, TLR1 remains unstudied using immunohistochemistry. TLRs are promising biomarkers, yet due to their diverse functions, further research is needed to clarify their roles in gastric cancer.

Therefore, in this study, we aimed to explore the tissue expression of TLR1, TLR2, TLR4, TLR5, TLR7, and TLR9 as potential prognostic biomarkers in gastric cancer patients, and to examine their associations with several clinicopathological variables.

\footnotetext{
Methods

Patients. We retrospectively studied 313 patients operated on for gastric cancer between 2000 and 2009 in the Department of Surgery, Helsinki University Hospital. Each gastric tumour was histologically confirmed as gastric adenocarcinoma by a pathologist of the Helsinki University Hospital. Individuals undergoing surgery were consecutively included in our patient cohort; we excluded patients with a history of malignant disease or any synchronous cancers. The median age at the time of surgery was 67.4 years (interquartile range [IQR] 57.1-76.5) and $152(48.6 \%)$ were male. The median follow-up time was 2.3 years, with $66(21.1 \%)$ patients alive at the end of follow-up. Living data until September 2017 were obtained from patient records, the Population Register Centre of Finland, and Statistics Finland. The five-year disease-specific survival for all patients was $43.3 \%$ (95\% confidence interval [CI] 37.4-49.2). We used the seventh version of the TNM classification for disease staging ${ }^{17}$.

The Surgical Ethics Committee of Helsinki University Hospital approved our study (Dnro HUS 226/E6/ 06, extension TMK02 \$66 17 April 2013). Permission to study archived tissue samples without individual consent was granted by the National Supervisory Authority of Welfare and Health (Valvira Dnro 10041/06.01.03.01/2012).
}

Tissue samples and immunohistochemistry. We applied the same immunohistochemical staining protocol to each TLR. A tissue microarrayer (TMA Grand Master, 3D Histech Ltd, Budapest, Hungary) was used to 


\begin{tabular}{|c|c|c|c|c|c|c|c|c|c|}
\hline & \multicolumn{3}{|l|}{ TLR1 } & \multicolumn{3}{|l|}{ TLR2 } & \multicolumn{3}{|l|}{ TLR4 } \\
\hline & Low (\%) & High (\%) & p value ${ }^{a}$ & Low (\%) & High (\%) & pvalue $^{a}$ & Low (\%) & High (\%) & p value $^{\mathrm{a}}$ \\
\hline \multicolumn{10}{|l|}{ Age, years } \\
\hline$<67$ & $76(54.3)$ & $64(45.7)$ & 0.074 & $61(44.9)$ & $75(55.1)$ & 0.080 & $55(39.3)$ & $85(60.7)$ & 0.245 \\
\hline$\geq 67$ & $62(43.7)$ & $80(56.3)$ & & $48(34.5)$ & $91(65.5)$ & & $46(32.6)$ & $95(67.4)$ & \\
\hline \multicolumn{10}{|l|}{ Gender } \\
\hline Male & $65(47.4)$ & $72(52.6)$ & 0.626 & $50(36.8)$ & $86(63.2)$ & 0.336 & $51(37.2)$ & $86(62.8)$ & 0.662 \\
\hline Female & $73(50.3)$ & $72(49.7)$ & & $59(42.4)$ & $80(57.6)$ & & $50(34.7)$ & $94(65.3)$ & \\
\hline \multicolumn{10}{|l|}{ Stage } \\
\hline I & $22(40.7)$ & $32(59.3)$ & 0.230 & $24(48.0)$ & $26(52.0)$ & 0.576 & $24(44.4)$ & $30(55.6)$ & 0.119 \\
\hline II & $30(46.2)$ & $35(53.8)$ & & $23(35.4)$ & $42(64.6)$ & & $17(26.2)$ & $48(73.8)$ & \\
\hline III & $59(56.7)$ & $45(43.3)$ & & $40(39.2)$ & $62(60.8)$ & & $35(34.0)$ & $68(66.0)$ & \\
\hline IV & 27 (46.6) & $31(53.4)$ & & $22(38.6)$ & $35(61.4)$ & & $25(43.1)$ & $33(56.9)$ & \\
\hline \multicolumn{10}{|c|}{ Tumour classification $(\mathrm{pT})$} \\
\hline pT1 & $19(45.2)$ & $23(54.8)$ & 0.912 & $23(57.5)$ & $17(42.5)$ & 0.043 & $21(50.0)$ & $21(50.0)$ & 0.049 \\
\hline pT2 & $20(47.6)$ & $22(52.4)$ & & $11(27.5)$ & $29(72.5)$ & & $13(31.0)$ & $29(69.0)$ & \\
\hline pT3 & $42(48.3)$ & $45(51.7)$ & & $31(36.5)$ & $54(63.5)$ & & $23(26.7)$ & $63(73.3)$ & \\
\hline pT4 & $57(51.4)$ & $54(48.6)$ & & $44(40.0)$ & $66(60.0)$ & & $44(39.6)$ & $67(60.4)$ & \\
\hline \multicolumn{10}{|c|}{ Lymph node metastasis (pN) } \\
\hline pN0 & 40 (43.5) & $52(56.5)$ & 0.251 & $38(43.2)$ & $50(56.8)$ & 0.415 & $33(35.9)$ & $59(64.1)$ & 0.745 \\
\hline pN1-3 & $92(50.8)$ & $89(49.2)$ & & $68(38.0)$ & $111(62.0)$ & & $61(33.9)$ & $119(66.1)$ & \\
\hline \multicolumn{10}{|c|}{ Distant metastasis (pM) } \\
\hline pM0 & $111(49.6)$ & $113(50.4)$ & 0.648 & 87 (39.9) & $131(60.1)$ & 0.857 & $76(34.1)$ & $147(65.9)$ & 0.202 \\
\hline $\mathrm{pM} 1$ & $27(46.6)$ & $31(53.4)$ & & $22(38.6)$ & $35(61.4)$ & & $25(43.1)$ & $33(56.9)$ & \\
\hline \multicolumn{10}{|c|}{ Laurén classification } \\
\hline Intestinal & $37(32.7)$ & $76(67.3)$ & $<0.001$ & $21(18.6)$ & $92(81.4)$ & $<0.001$ & $22(19.5)$ & $91(80.5)$ & $<0.001$ \\
\hline Diffuse & $101(59.8)$ & $68(40.2)$ & & $88(54.3)$ & $74(45.7)$ & & $79(47.0)$ & $89(53.0)$ & \\
\hline
\end{tabular}

Table 2. Association of TLR1, TLR2, and TLR4 expressions with clinicopathologic variables in 313 gastric

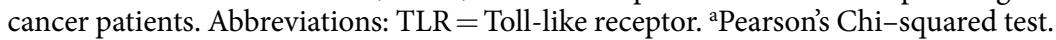

punch four 1.0-mm cores from each sample, embedding them in a recipient block of paraffin. The TMA samples were subsequently cut in $4-\mu \mathrm{m}$ sections for the immunohistochemical staining, resulting in four 1.0 -mm tissue microarray spots per patient. The slides were deparaffined, pre-warmed in a PT module (LabVision UK Ltd, UK) to $65^{\circ} \mathrm{C}$, and treated for $20 \mathrm{~min}$ in $98^{\circ} \mathrm{C}$ for antigen retrieval (Tris-EDTA buffer; $\mathrm{pH} 9.0$ or Tris-Hcl buffer; $\mathrm{pH}$ 8.5). The staining was performed in an Autostainer 480 (LabVision) with the Dako detection system (Dako REAL EnVision Detection System, Peroxidase/DAB+, Rabbit/Mouse [Dako, Glostrup, Denmark]). Endogenous peroxidases were blocked with the $0.3 \%$ Dako REAL Peroxidase-Blocking Solution. The slides were then incubated with the primary antibody, using the following primary antibodies: TLR 1 rabbit polyclonal $200 \mu \mathrm{g} / \mathrm{ml}(1: 100$, $1 \mathrm{hr}, \mathrm{sc}-30000$, Santa Cruz Biotechnology, Dallas, TX, USA), TLR2 rabbit polyclonal $200 \mu \mathrm{g} / \mathrm{ml}$ (1:200, over-night (O/N), sc-10739, Santa Cruz Biotechnology), TLR4 mouse monoclonal IgG1 200 $\mu \mathrm{g} / \mathrm{ml}$ (1:2000, $1 \mathrm{hr}, \mathrm{sc}-293072$, Santa Cruz Biotechnology), TLR5 mouse monoclonal $0.1 \mathrm{mg} / \mathrm{ml}(1: 100,1 \mathrm{hr}$, NBP2-24787, Novus Biologicals, Centennial, CO, USA), TLR7 rabbit polyclonal $1.0 \mu \mathrm{g} / \mathrm{ml}$ (1:500, $1 \mathrm{hr}$, NBP2-24906, Novus Biologicals), and TLR9 mouse monoclonal $100 \mu \mathrm{g} / \mathrm{ml}(1: 300, \mathrm{O} / \mathrm{N}$, sc-52966, Santa Cruz Biotechnology). Finally, the samples were incubated with the peroxidase-conjugated Dako REAL EnVision/HRP, Rabbit/Mouse (ENV) secondary antibody for $30 \mathrm{~min}$, visualised using the Dako REAL DAB + Chromogen (10 min), and counterstained with Meyer's hematoxylin.

Scoring of immunoreactivities. We scored TLR1 immunoreactivity on 282 tissue cores, TLR2 on 275 cores, TLR 4 on 281 cores, TLR5 on 277 cores, TLR7 on 268 cores, and TLR9 on 277 cores. We excluded cores lacking cancer tissue. Among all TLRs, reactivity was observed both in the nuclei and in the cytoplasm. We quantified TLR expression by scoring the cancer cells' cytoplasmic staining intensity. A score of 3 indicated strong staining, 2 moderate, 1 weak, and 0 signified the absence of staining. A total of four tissue cores per tumour sample were evaluated, from which we selected the tumour core with the highest score to represent each patient in the statistical analyses. For the final analyses, data were divided into two categories: high expression (strong or moderate immunoreactivity) and low expression (weak or no immunoreactivity) groups (Fig. 1). All tissue microarray cores were scored by two independent researchers, including an experienced pathologist from the Department of Pathology and Oral Pathology at the University of Helsinki (Aa.K. and J.H.), both blinded to the clinical data. Tissue core scores with any difference between researchers were re-evaluated, and the final score was reached through discussion and consensus. 


\begin{tabular}{|c|c|c|c|c|c|c|c|c|c|}
\hline & \multicolumn{3}{|l|}{ TLR5 } & \multicolumn{3}{|l|}{ TLR7 } & \multicolumn{3}{|l|}{ TLR9 } \\
\hline & Low (\%) & High (\%) & p value ${ }^{a}$ & Low (\%) & High (\%) & pvalue $^{\mathrm{a}}$ & Low (\%) & High (\%) & pvalue $^{\mathrm{a}}$ \\
\hline \multicolumn{10}{|l|}{ Age, years } \\
\hline$<67$ & $92(67.2)$ & $45(32.8)$ & 0.028 & $74(56.5)$ & $57(43.5)$ & 0.315 & $80(58.0)$ & $58(42.0)$ & 0.001 \\
\hline$\geq 67$ & $76(54.3)$ & $64(45.7)$ & & $69(50.4)$ & $68(49.6)$ & & $54(38.8)$ & $85(61.2)$ & \\
\hline \multicolumn{10}{|l|}{ Gender } \\
\hline Male & $75(56.0)$ & $59(44.0)$ & 0.123 & $61(46.2)$ & $71(53.8)$ & 0.021 & $60(44.4)$ & $75(55.6)$ & 0.202 \\
\hline Female & $93(65.0)$ & $50(35.0)$ & & $82(60.3)$ & $54(39.7)$ & & $74(52.1)$ & $68(47.9)$ & \\
\hline \multicolumn{10}{|l|}{ Stage } \\
\hline I & $29(54.7)$ & $24(45.3)$ & 0.255 & $35(71.4)$ & $14(28.6)$ & 0.030 & $24(46.2)$ & $28(53.8)$ & 0.961 \\
\hline II & $36(55.4)$ & $29(44.6)$ & & 28 (43.8) & $36(56.3)$ & & $31(47.7)$ & $34(52.3)$ & \\
\hline III & $64(62.1)$ & $39(37.9)$ & & $53(52.5)$ & $48(47.5)$ & & $52(50.5)$ & $51(49.5)$ & \\
\hline IV & $39(70.9)$ & $16(29.1)$ & & $27(50.9)$ & $26(49.1)$ & & $27(48.2)$ & $29(51.8)$ & \\
\hline \multicolumn{10}{|c|}{ Tumour classification (pT) } \\
\hline pT1 & $22(52.4)$ & $20(47.6)$ & 0.616 & $28(73.7)$ & $10(26.3)$ & 0.025 & $20(48.8)$ & $21(51.2)$ & 0.260 \\
\hline pT2 & $24(60.0)$ & $16(40.0)$ & & $20(51.3)$ & $19(48.7)$ & & $14(34.1)$ & 27 (65.9) & \\
\hline pT3 & $52(60.5)$ & $34(39.5)$ & & $37(44.0)$ & $47(56.0)$ & & $43(50.6)$ & $42(49.4)$ & \\
\hline pT4 & $70(64.2)$ & $39(35.8)$ & & $58(54.2)$ & $49(45.8)$ & & $57(51.8)$ & $53(48.2)$ & \\
\hline \multicolumn{10}{|c|}{ Lymph node metastasis (pN) } \\
\hline pNo & $48(53.3)$ & $42(46.7)$ & 0.090 & 49 (56.3) & $38(43.7)$ & 0.483 & $45(50.0)$ & $45(50.0)$ & 0.634 \\
\hline pN1-3 & $114(64.0)$ & $64(36.0)$ & & $90(51.7)$ & $84(48.3)$ & & $84(46.9)$ & $95(53.1)$ & \\
\hline \multicolumn{10}{|c|}{ Distant metastasis (pM) } \\
\hline $\mathrm{pM} 0$ & $129(58.1)$ & $93(41.9)$ & 0.082 & $116(54.0)$ & $99(46.0)$ & 0.694 & $107(48.4)$ & $114(51.6)$ & 0.978 \\
\hline pM1 & $39(70.9)$ & $16(29.1)$ & & $27(50.9)$ & $26(49.1)$ & & $27(48.2)$ & $29(51.8)$ & \\
\hline \multicolumn{10}{|c|}{ Laurén classification } \\
\hline Intestinal & 49 (43.4) & $64(56.6)$ & $<0.001$ & $33(29.7)$ & $78(70.3)$ & $<0.001$ & $26(23.2)$ & $86(76.8)$ & $<0.001$ \\
\hline Diffuse & $119(72.6)$ & $45(27.4)$ & & $110(70.1)$ & $47(29.9)$ & & $108(65.5)$ & $57(34.5)$ & \\
\hline
\end{tabular}

Table 3. Association of TLR5, TLR7, and TLR9 expressions with clinicopathologic variables in 313 gastric

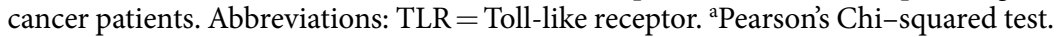

\begin{tabular}{|l|l|l|l|l|l|l|l|l|l|l|}
\hline & \multicolumn{3}{l}{ TLR1 } & \multicolumn{3}{l|}{ TLR2 } & \multicolumn{3}{l|}{ TLR4 } & \multicolumn{2}{l|}{ TLR5 } & \multicolumn{2}{l|}{ TLR7 } \\
\cline { 2 - 12 } & $\mathbf{r}_{\mathbf{s}}$ & $\mathbf{p}$ value & $\mathbf{r}_{\mathbf{s}}$ & $\mathbf{p}$ value & $\mathbf{r}_{\mathbf{s}}$ & $\mathbf{p}$ value & $\mathbf{r}_{\mathrm{s}}$ & $\mathbf{p}$ value & $\mathbf{r}_{\mathrm{s}}$ & $\mathbf{p}$ value \\
\hline TLR2 & 0.314 & $<0.001$ & & & & & & & & \\
\hline TLR4 & 0.293 & $<0.001$ & 0.436 & $<0.001$ & & & & & & \\
\hline TLR5 & 0.345 & $<0.001$ & 0.272 & $<0.001$ & 0.212 & $<0.001$ & & & & \\
\hline TLR7 & 0.296 & $<0.001$ & 0.401 & $<0.001$ & 0.332 & $<0.001$ & 0.253 & $<0.001$ & & \\
\hline TLR9 & 0.422 & $<0.001$ & 0.384 & $<0.001$ & 0.361 & $<0.001$ & 0.267 & $<0.001$ & 0.338 & $<0.001$ \\
\hline
\end{tabular}

Table 4. Correlation of TLR1, TLR2, TLR4, TLR5, TLR7, and TLR9 expressions among each other in 313 gastric cancer patients. Abbreviations: $T L R=$ Toll-like receptor, $\mathrm{r}_{\mathrm{s}}=$ Spearman's rank correlation coefficient.

Statistical analyses. Associations and correlations were evaluated using the Pearson's chi-squared test and the Spearman's rank correlation test. We created the survival curves using the Kaplan-Meier method and compared them using the log-rank test. Disease-specific survival was determined from the date of surgery until death from gastric cancer or until the end of the follow-up period. We applied the Cox proportional hazard model to calculate the hazard ratios for the uni- and multivariate survival analyses. For the multivariate survival analysis, we included age, stage, the Laurén classification, and TLR5 expression in our model. Stage was processed as a categorical covariate, and we found no significant interaction terms. For all analyses, we considered a two tailed $\mathrm{p}<0.05$ as statistically significant, and for all statistical analyses we used IBM SPSS Statistics version 24.0 for Mac (IBM Corporation, Armonk, NY, USA).

\section{Results}

Associations between TLR expression and clinicopathological variables. Table 1 summarises the distribution of immunoreactivities. A high TLR2 and a high TLR4 expression associated with pT2-4 tumours $(\mathrm{p}=0.043 ; \mathrm{p}=0.049$; Table 2$)$, and a high TLR7 expression associated with $\mathrm{pT} 3$ tumours $(\mathrm{p}=0.025$; Table 3$)$. In addition, a high TLR7 expression associated with stage II disease $(\mathrm{p}=0.030)$ and with being male $(\mathrm{p}=0.021)$. A high TLR5 and a high TLR9 expression associated with an older age $(\mathrm{p}=0.028 ; \mathrm{p}=0.001)$. Furthermore, a high expression of each TLR studied associated with the intestinal-type cancer $(\mathrm{p}<0.001$ for all). Lastly, a high 


\begin{tabular}{|c|c|c|c|c|c|c|}
\hline & \multicolumn{3}{|c|}{ Univariate } & \multicolumn{3}{|c|}{ Multivariate } \\
\hline & HR & $95 \% \mathrm{CI}$ & p value & HR & $95 \% \mathrm{CI}$ & p value \\
\hline \multicolumn{7}{|l|}{ Age, years } \\
\hline$<67$ & 1.00 & & & 1.00 & & \\
\hline$\geq 67$ & 1.33 & $1.00-1.79$ & 0.054 & 2.60 & $1.85-3.66$ & $<0.001$ \\
\hline \multicolumn{7}{|l|}{ Stage } \\
\hline I & 1.00 & & & 1.00 & & \\
\hline II & 5.44 & $2.25-13.1$ & $<0.001$ & 4.86 & $1.85-12.8$ & 0.001 \\
\hline III & 15.7 & $6.85-36.1$ & $<0.001$ & 17.3 & 6.99-43.0 & $<0.001$ \\
\hline IV & 46.2 & 19.6-109 & $<0.001$ & \begin{tabular}{|l|}
63.2 \\
\end{tabular} & $24.5-163$ & $<0.001$ \\
\hline \multicolumn{7}{|c|}{ Laurén classification } \\
\hline Intestinal & 1.00 & & & 1.00 & & \\
\hline Diffuse & 1.45 & $1.06-1.98$ & 0.020 & 1.53 & $1.09-2.17$ & 0.016 \\
\hline \multicolumn{7}{|l|}{ TLR1 } \\
\hline Low & 1.00 & & & & & \\
\hline High & 0.83 & $0.61-1.13$ & 0.225 & & & \\
\hline \multicolumn{7}{|l|}{ TLR2 } \\
\hline Low & 1.00 & & & & & \\
\hline High & 0.96 & $0.70-1.31$ & 0.774 & & & \\
\hline \multicolumn{7}{|l|}{ TLR4 } \\
\hline Low & 1.00 & & & & & \\
\hline High & 0.80 & $0.59-1.10$ & 0.166 & & & \\
\hline \multicolumn{7}{|l|}{ TLR5 } \\
\hline Low & 1.00 & & & 1.00 & & \\
\hline High & 0.66 & \begin{tabular}{|l|}
$0.47-0.92$ \\
\end{tabular} & 0.014 & 0.73 & \begin{tabular}{|l|}
$0.52-1.05$ \\
\end{tabular} & 0.086 \\
\hline \multicolumn{7}{|l|}{ TLR7 } \\
\hline Low & 1.00 & & & & & \\
\hline High & 0.90 & $0.66-1.24$ & 0.521 & & & \\
\hline \multicolumn{7}{|l|}{ TLR9 } \\
\hline Low & 1.00 & & & & & \\
\hline High & 0.85 & $0.62-1.16$ & 0.298 & & & \\
\hline
\end{tabular}

Table 5. Uni- and multivariate survival analyses for 313 gastric cancer patients. Abbreviations: TLR $=$ Toll-like receptor, $\mathrm{CI}=$ Confidence interval, $\mathrm{HR}=$ Hazard ratio.

expression of each TLR studied associated with high expressions of all other TLRs, whilst comparisons also revealed weak to moderate positive correlations $(\mathrm{p}<0.001$ for all; Table 4 and Supplementary Table 1$)$.

Survival analyses. The five-year disease-specific survival amongst gastric cancer patients with a high TLR5 expression was 53.4\% (95\% CI 43.4-63.4), compared to $37.6 \%$ (95\% CI 30.0-45.2) among those with a low TLR5 expression ( $\mathrm{p}=0.014$; Table 5 and Fig. 2D). TLR1, TLR2, TLR4, TLR7, and TLR9 expressions did not function as significant prognostic biomarkers across the entire cohort (Fig. 2). In the multivariate survival analysis, significant prognostic factors consisted of age, stage, and the Laurén classification (Table 5).

In the subgroup analyses, a high TLR5 expression emerged as an indicator of a better prognosis amongst patients with stage II disease (hazard ratio [HR] 0.33; 95\% CI 0.13-0.83; $\mathrm{p}=0.019 ;$ Fig. 3A), amongst younger patients (HR 0.55; 95\% CI 0.32-0.95; $\mathrm{p}=0.033$ ), amongst those with no distant metastasis (HR 0.66; 95\% CI $0.44-0.99 ; p=0.044$ ), and amongst those with an intestinal-type cancer (HR 0.58; 95\% CI 0.34-0.98; $\mathrm{p}=0.043$ : Fig. 3B), but not amongst those with a diffuse-type cancer (HR 0.83; 95\% CI 0.53-1.31; $\mathrm{p}=0.417$; Table 6 and Fig. 3C). Amongst patients with a high TLR7 expression and stage I disease, no deaths due to gastric cancer were recorded during our follow-up period (HR 0.03; 95\% CI 0.01-97.7; $\mathrm{p}=0.392$; Fig. 3D). Moreover, a high TLR7 expression indicated a better prognosis amongst patients with stage III disease (HR 0.60; 95\% CI 0.38-0.95; $p=0.029$; Fig. 3E), amongst those with a pT4 tumour (HR 0.51; 95\% CI 0.32-0.80, $p=0.003$ ), and amongst those with lymph-node metastasis (HR 0.67; 95\% CI 0.47-0.96; $\mathrm{p}=0.029$ ). Furthermore, a high TLR9 expression indicated a better prognosis amongst patients with stage II disease (HR 0.30; 95\% CI 0.12-0.76; $\mathrm{p}=0.011$; Fig. 3F). Lastly, TLR1, TLR2, and TLR4 expression levels did not significantly predict the outcome in any patient subgroup (Supplementary Table 2).

\section{Discussion}

In this study, we show for the first time that a high TLR5 tissue expression may identify gastric cancer patients with a favourable outcome, particularly amongst those with stage II disease, an intestinal-type cancer, without distant metastases or a younger age. In addition to TLR5, TLR1, TLR2, TLR4, TLR7, and TLR9 were also expressed in gastric cancer tissues, yet their expression levels did not function as prognostic biomarkers across 
A

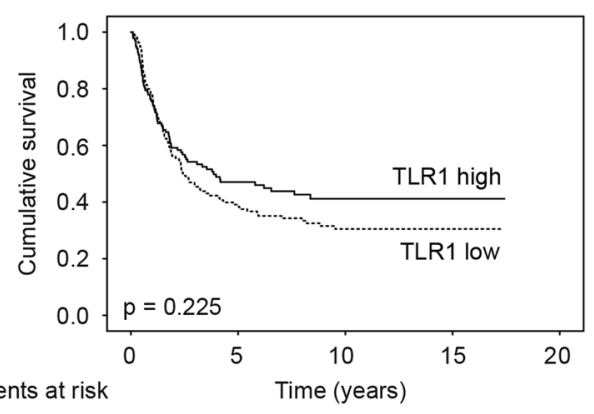

$\begin{array}{llllll}\text { TLR1 low: } & 138 & 49 & 25 & 5 & 0 \\ \text { TLR1 high: } & 144 & 50 & 21 & 5 & 0\end{array}$

C

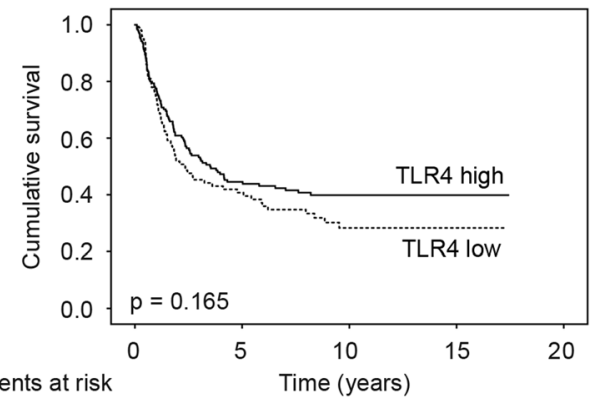

TLR4 low: $\quad 101$ TLR4 high: 180

$\begin{array}{llll}35 & 12 & 3 & 0 \\ 64 & 34 & 7 & 0\end{array}$

E

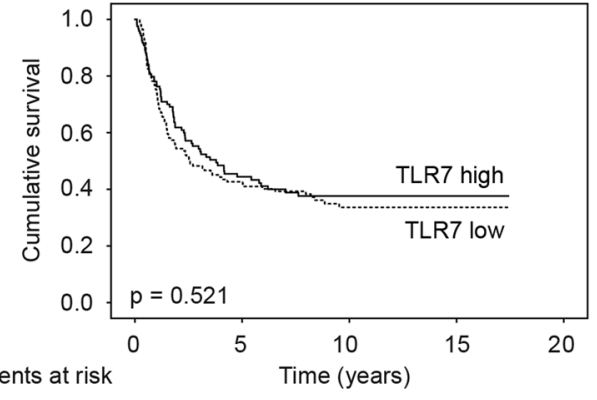

TLR7 low: $143 \quad 52 \quad 23 \quad 350$
B

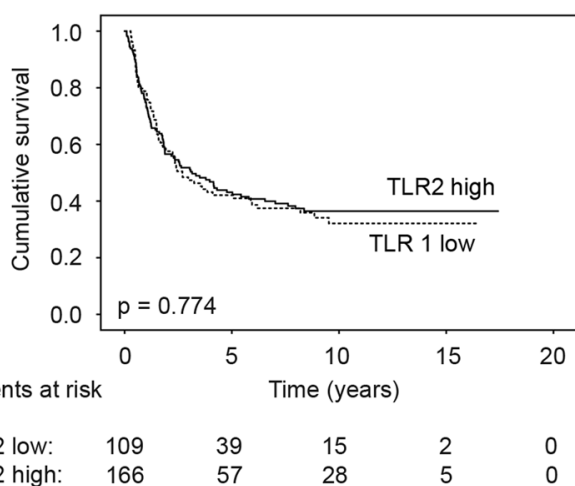

D

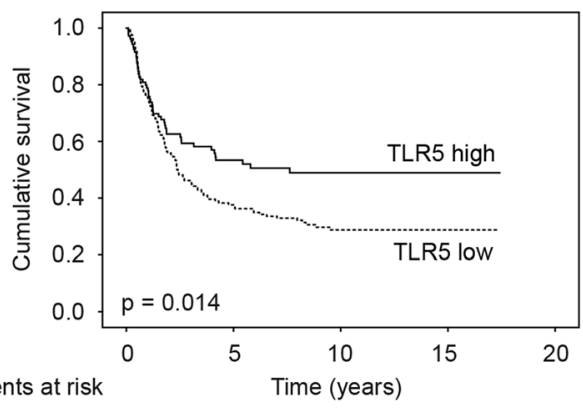

$\begin{array}{llllll}\text { TLR5 low: } & 168 & 56 & 29 & 7 & 0\end{array}$

TLR5 high: $109 \quad 43 \quad 17$

$\mathbf{F}$

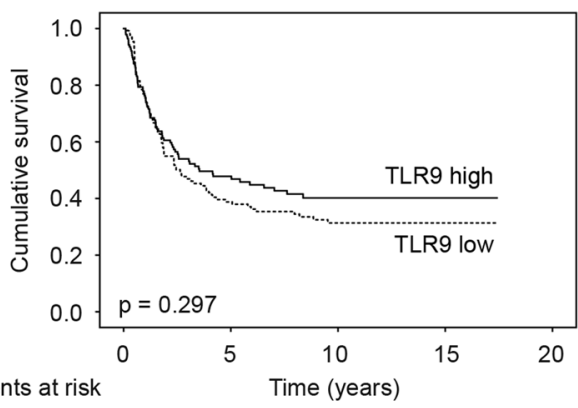

\begin{tabular}{llllll} 
TLR9 low: & 134 & 47 & 27 & 7 & 0 \\
\hline & 143 & 51 & 18 & 3 & 0
\end{tabular}

Figure 2. Gastric cancer patients' disease-specific survival according to the Kaplan-Meier method, with $p$ values for significance based on the log-rank test. High (A) TLR1, (B) TLR2, (C) TLR4, (D) TLR5, (E) TLR7, and (F) TLR9 expressions compared to low expressions.

the entire patient cohort. Furthermore, we showed that a high TLR7 expression may identify patients with a better prognosis amongst those with an advanced disease. High expressions of each of TLR studied associated with an intestinal-type cancer, suggesting that the inflammatory activity in the gastric mucosa is stronger in intestinalthan in diffuse-type tumours. Moreover, the high expressions of each TLR studied also associated with high expressions of all other TLRs.

In comparison to our results, Park et al. ${ }^{14}$ found that TLR5 activation via flagellin enhanced the proliferation of gastric cancer cells in vitro. Our results differ through the application of immunohistochemistry on surgical patient samples, where we show that the prognosis amongst gastric cancer patients with a high TLR5 expression is better than amongst those with a low tumour tissue expression. This discrepancy may result from the fact that Park et al. completed in vitro studies, whereas we conducted an in vivo study, rending the results not directly comparable.

TLR3, TLR4, and TLR9 were previously studied in a smaller gastric cancer patient series using a methodology similar to ours, relying on immunohistochemistry and tissue microarrays ${ }^{12}$. Similar to our findings, that study 
A

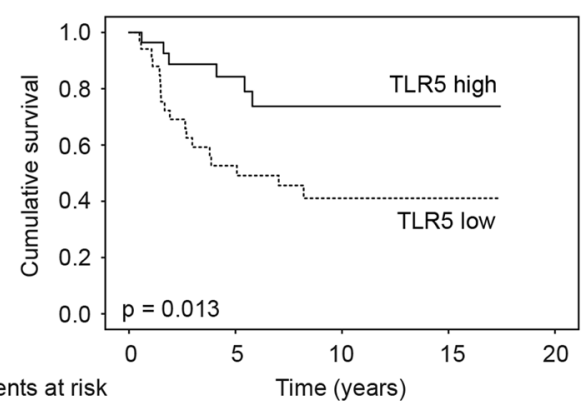

$\begin{array}{llllll}\text { TLR5 low: } & 36 & 15 & 8 & 2 & 0 \\ \text { TLR5 high: } & 29 & 18 & 6 & 2 & 0\end{array}$

C

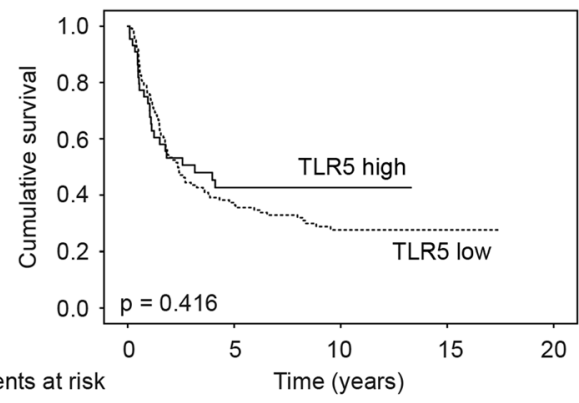

TLR5 low: $\begin{array}{lllll}119 & 42 & 23 & 7 & 0\end{array}$

$\mathbf{E}$

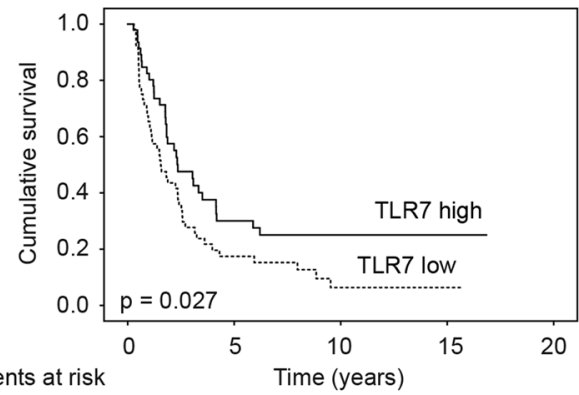

$\begin{array}{lccccc}\text { TLR7 low: } & 53 & 8 & 2 & 1 & 0 \\ \text { TLR7 high: } & 48 & 12 & 7 & 1 & 0\end{array}$
B

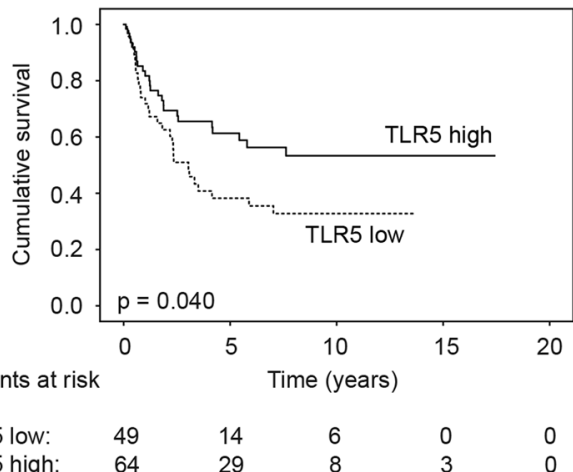

D

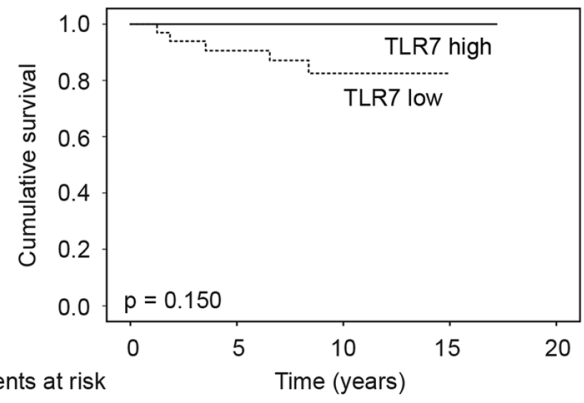

$\begin{array}{llllll}\text { TLR7 low: } & 35 & 27 & 14 & 1 & 0\end{array}$

$\begin{array}{llllll}\text { TLR7 high: } & 14 & 12 & 5 & 2 & 0\end{array}$

$\mathbf{F}$

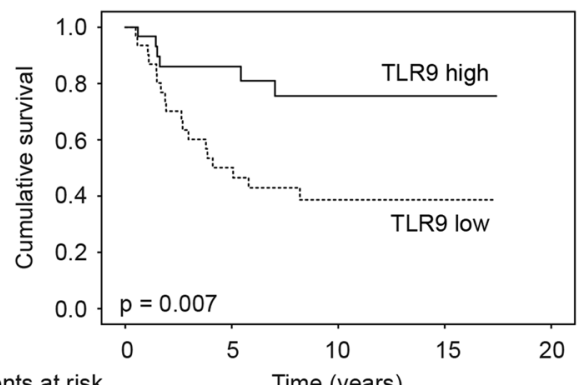

$\begin{array}{llllll}\text { TLR9 low: } & 31 & 14 & 6 & 1 & 0 \\ \text { TLR9 high: } & 34 & 19 & 8 & 3 & 0\end{array}$

Figure 3. Gastric cancer patients' disease-specific survival by subgroup according to the Kaplan-Meier method, with $\mathrm{p}$ values for significance based on the log-rank test. A high versus a low TLR5 expression amongst patients with (A) stage II disease, (B) an intestinal-, and (C) a diffuse-type cancer. A high versus a low TLR7 expression amongst patients with (D) stage I and (E) stage III disease. (F) A high versus a low TLR9 expression amongst patients with stage II disease.

concluded that TLR4 and TLR9 expression levels did not significantly predict outcome in gastric cancer patients. Interestingly, in that study, a high TLR3 expression appeared to associate with a poor prognosis. Unfortunately, TLR3 was not included in our panel of biomarkers. In another study amongst 47 gastric cancer samples studied using immunohistochemistry, a high TLR2 expression associated with metastatic disease ${ }^{13}$. We found that a high TLR2 expression associated with an intestinal-type cancer, but not with any other clinicopathological variables. In the previous study, quantification of TLR expression levels relied on both the intensity and percentage of stained cells, whereas we only evaluated staining intensity.

TLR7 was previously thought to reduce the viability of gastric cancer cells ${ }^{15}$. Accordingly, we found that prognosis was better amongst patients with a high TLR7 expression in several subgroups, particularly among those with locally advanced disease. Interestingly, we recorded no gastric cancer-related deaths among stage I patients with a high TLR7 expression. Although patients with stage I disease typically enjoy a good overall prognosis, it is 


\begin{tabular}{|c|c|c|c|c|c|c|c|c|c|}
\hline & \multicolumn{3}{|c|}{ High TLR5 } & \multicolumn{3}{|c|}{ High TLR7 } & \multicolumn{3}{|c|}{ High TLR9 } \\
\hline & HR & $95 \% \mathrm{CI}$ & p value & HR & $95 \% \mathrm{CI}$ & p value & HR & $95 \% \mathrm{CI}$ & p value \\
\hline \multicolumn{10}{|l|}{ Age, years } \\
\hline$<67$ & 0.55 & $0.32-0.95$ & 0.033 & 1.07 & $0.67-1.73$ & 0.767 & 0.90 & $0.56-1.43$ & 0.648 \\
\hline$\geq 67$ & 0.66 & $0.42-1.02$ & 0.059 & 0.72 & $0.47-1.10$ & 0.131 & 0.69 & $0.45-1.05$ & 0.086 \\
\hline \multicolumn{10}{|l|}{ Gender } \\
\hline Male & 0.68 & $0.42-1.10$ & 0.114 & 0.98 & $0.62-1.56$ & 0.932 & 0.82 & $0.52-1.30$ & 0.400 \\
\hline Female & 0.63 & $0.39-1.02$ & 0.058 & 0.84 & $0.54-1.31$ & 0.443 & 0.87 & $0.57-1.34$ & 0.534 \\
\hline \multicolumn{10}{|l|}{ Stage } \\
\hline I & 0.41 & $0.05-3.67$ & 0.423 & 0.03 & $0.01-97.7$ & 0.392 & 1.59 & $0.26-9.63$ & 0.613 \\
\hline II & 0.33 & $0.13-0.83$ & 0.019 & 0.79 & $0.35-1.79$ & 0.572 & 0.30 & $0.12-0.76$ & 0.011 \\
\hline III & 0.96 & $0.60-1.52$ & 0.853 & 0.60 & $0.38-0.95$ & 0.029 & 0.93 & $0.60-1.44$ & 0.728 \\
\hline IV & 0.97 & $0.51-1.85$ & 0.923 & 0.87 & $0.48-1.56$ & 0.634 & 1.23 & $0.71-2.16$ & 0.461 \\
\hline \multicolumn{10}{|c|}{ Tumour classification ( $\mathrm{pT}$ ) } \\
\hline pT1 & 0.44 & $0.05-4.23$ & 0.476 & \multicolumn{3}{|l|}{ N/A } & 0.34 & $0.04-3.25$ & 0.348 \\
\hline pT2 & 0.72 & $0.19-2.73$ & 0.629 & 0.99 & $0.30-3.24$ & 0.984 & 1.55 & $0.46-5.21$ & 0.476 \\
\hline pT3 & 0.58 & $0.33-1.01$ & 0.056 & 0.93 & $0.55-1.57$ & 0.798 & 0.99 & $0.59-1.66$ & 0.956 \\
\hline pT4 & 0.76 & $0.48-1.19$ & 0.229 & 0.51 & $0.32-0.80$ & 0.003 & 0.86 & $0.56-1.31$ & 0.470 \\
\hline \multicolumn{10}{|c|}{ Lymph node metastasis $(\mathrm{pN})$} \\
\hline pNo & 0.69 & $0.31-1.54$ & 0.364 & 1.66 & $0.78-3.53$ & 0.190 & 0.67 & $0.31-1.47$ & 0.317 \\
\hline $\mathrm{pN} 1-3$ & 0.69 & $0.47-1.02$ & 0.062 & 0.67 & $0.47-0.96$ & 0.029 & 0.81 & $0.57-1.16$ & 0.250 \\
\hline \multicolumn{10}{|c|}{ Distant metastasis (pM) } \\
\hline $\mathrm{pM} 0$ & 0.66 & $0.44-0.99$ & 0.044 & 0.82 & $0.56-1.20$ & 0.307 & 0.73 & $0.50-1.06$ & 0.101 \\
\hline pM1 & 0.97 & $0.51-1.85$ & 0.923 & 0.87 & $0.48-1.56$ & 0.634 & 1.23 & $0.71-2.16$ & 0.461 \\
\hline \multicolumn{10}{|c|}{ Laurén classification } \\
\hline Intestinal & 0.58 & $0.34-0.98$ & 0.043 & 1.06 & $0.58-1.96$ & 0.844 & 0.80 & $0.44-1.45$ & 0.460 \\
\hline Diffuse & 0.83 & $0.53-1.31$ & 0.417 & 1.05 & $0.69-1.62$ & 0.812 & 1.06 & $0.70-1.58$ & 0.794 \\
\hline
\end{tabular}

Table 6. Survival analyses by subgroups, high TLR5, TLR7, and TLR9 expressions compared to low in 313 gastric cancer patients. Abbreviations: $\mathrm{TLR}=$ Toll-like receptor, $\mathrm{CI}=$ Confidence interval, $\mathrm{HR}=\mathrm{Hazard}$ ratio, $\mathrm{N} / \mathrm{A}=$ not available.

very surprising that no deaths due to gastric cancer were recorded. Unfortunately, the number of patients in this subgroup was too small to draw definitive conclusions; our results, however, encourage further study of TLR7 expression in early-stage gastric cancer.

TLR-related therapy, particularly TLR agonists, capable of activating the immune system against cancer have been broadly studied in several malignancies ${ }^{18,19}$. The administration of a TLR7 agonist, imiquimod, increases the expression of TLR7 in gastric cancer cells and reduces their viability ${ }^{15}$. Whether imiquimod has direct cytotoxic effects or if acting via the modulation of inflammatory cell activity remain incompletely understood since numerous different pathways are involved. In vitro studies of imiquimod on colon and basal cell carcinoma cells suggest that it can directly induce cell death ${ }^{20,21}$.

In addition, gastric cancer predisposing H. pylori infection induces polymorphous TLR expression in the gastric mucosa, since TLRs are essential for immunity against $i^{22-25}$. Genetic variations of TLR1, TLR5, and TLR9 may contribute to the malignant transformation of the gastric mucosa by altering the immune response to $H$. pylori ${ }^{16,26,27}$. On the other hand, a TLR2 polymorphism was recently shown to function as a potential prognostic biomarker in gastric cancer patients independent of $H$. pylori infection status, suggesting that gastric carcinogenesis affecting signalling pathways does not merely limit to crosstalk with $H$. pylori ${ }^{28}$. Conversely, we identified no TLR2 protein expression that functioned as a prognostic biomarker in gastric cancer patients, although the results related to protein expression and gene polymorphism analyses are not directly comparable. Unfortunately, in our retrospective study, patients' serum antibody levels against $H$. pylori were unavailable and the $H$. pylori infection status from the archived tissue samples was impossible to reliably determine.

The strengths of this study include the large patient cohort with precise and reliable follow-up information and the uniformity of laboratory methods used to determine the expression levels of TLRs. Yet, the single-centre setting introduces a bias and limits the generalisability of our results. Additional studies on other well-defined patient cohorts are needed in order to validate our results. Furthermore, in addition to H. pylori infection status, the limitations of this study include the lack of information for certain other well-known risk factors in our gastric cancer cases, such as venous and perineural invasion, lymphatic emboli, and the tumour subsite. Accessing details regarding each of these factors in a retrospective manner may potentially introduce inaccuracies and, thus, we did not include them in our analyses. Automated digital scoring systems have proved beneficial in improving the reproducibility of evaluating the visual density of immunohistochemically stained samples ${ }^{29}$. Some automated digital systems can already identify individual cells; however, the available systems cannot yet reliably interpret the cells' morphological features, and, thus, identify malignant cells from the stroma ${ }^{30-32}$. Studying heterogeneous tissues, reliably identifying neoplastic cells from non-neoplastic cells remain essential in order to produce 
reproducible data. Furthermore, in the context of toll-like receptors, the tumour microenvironment's immune cell toll-like receptor expression limits the application of the digital colourimetric quantification of tissue cores. Thus, in this study, digital colourimetric quantification of tissue cores was, unfortunately, not possible.

To conclude, in this study we show, for the first time, that a high TLR5 tissue expression may identify gastric cancer patients with a better prognosis, particularly amongst those with a stage II disease or an intestinal-type cancer. In a small subgroup of stage I disease, none of the patients with a high TLR7 expression died from gastric cancer. In addition, we found that a high expression of TLR1, TLR2, TLR4, TLR5, TLR7, and TLR9 associated with an intestinal-type gastric cancer and with a high expression of all other TLRs.

\section{Data Availability}

All data and materials are available from the corresponding author upon request.

\section{References}

1. Bray, F. et al. Global cancer statistics 2018: GLOBOCAN estimates of incidence and mortality worldwide for 36 cancers in 185 countries. CA. Cancer J. Clin. 68, 394-424 (2018).

2. Canavan, C., Abrams, K. R. \& Mayberry, J. Meta-analysis: colorectal and small bowel cancer risk in patients with Crohn's disease. Aliment. Pharmacol. Ther. 23, 1097-1104 (2006).

3. Francescone, R., Hou, V. \& Grivennikov, S. I. Cytokines, IBD, and colitis-associated cancer. Inflamm. Bowel Dis. 21, 409-18 (2015).

4. West, A. \& Jenkins, B. Inflammatory and Non-Inflammatory Roles for Toll-Like Receptors in Gastrointestinal Cancer. Curr. Pharm. Des. 21, 2968-2977 (2015).

5. Akira, S., Uematsu, S. \& Takeuchi, O. Pathogen Recognition and Innate Immunity. Cell 124, 783-801 (2006).

6. Hernandez, C., Huebener, P. \& Schwabe, R. F. Damage-associated molecular patterns in cancer: a double-edged sword. Oncogene 35, 5931-5941 (2016).

7. Pradere, J.-P., Dapito, D. H. \& Schwabe, R. F. The Yin and Yang of Toll-like receptors in cancer. Oncogene 33, 3485-95 (2014).

8. Pimentel-Nunes, P. et al. Increased Expression of Toll-like Receptors (TLR) 2, 4 and 5 in Gastric Dysplasia. Pathol. Oncol. Res. 17, 677-683 (2011).

9. Zhou, Q. et al. Association between TLR4 (+896A/G and +1196C/T) Polymorphisms and Gastric Cancer Risk: An Updated MetaAnalysis. PLoS One 9, e109605 (2014).

10. Castaño-Rodríguez, N., Kaakoush, N. O., Goh, K.-L., Fock, K. M. \& Mitchell, H. M. The Role of TLR2, TLR4 and CD14 Genetic Polymorphisms in Gastric Carcinogenesis: A Case-Control Study and Meta-Analysis. PLoS One 8, e60327 (2013).

11. Wang, N., An, D., Li, Q., Li, C. \& Yang, G. Effect of Toll-like receptor 4 signaling activation on the biological behavior of gastric cancer cell lines. Zhonghua Yi Xue Za Zhi 95, 2104-8 (2015).

12. Fernandez-Garcia, B. et al. Clinical Significance of Toll-like Receptor 3, 4, and 9 in Gastric Cancer. J. Immunother. 37, 77-83 (2014).

13. Yang, H. et al. Toll-like receptor 2 promotes invasion by SGC-7901 human gastric carcinoma cells and is associated with gastric carcinoma metastasis. Ann. Clin. Lab. Sci. 44, 158-66 (2014).

14. Park, J.-H. et al. Flagellin promotes the proliferation of gastric cancer cells via the Toll-like receptor 5. Int. J. Mol. Med. 28, 115-9 (2011).

15. Jiang, J. et al. Decreased expression of TLR7 in gastric cancer tissues and the effects of TLR7 activation on gastric cancer cells. Oncol. Lett. 12, 631-636 (2016).

16. Ravishankar Ram, M. et al. Polymorphisms at Locus 4p14 of Toll-Like Receptors TLR-1 and TLR-10 Confer Susceptibility to Gastric Carcinoma in Helicobacter pylori Infection. PLoS One 10, e0141865 (2015).

17. Sobin, L. H., Gospodarowicz, M. K. \& Wittekind, C. TNM Classification of Malignant Tumours. (Wiley, 2011).

18. Mikulandra, M., Pavelic, J. \& Glavan, T. M. Recent Findings on the Application of Toll-like Receptors Agonists in Cancer Therapy. Curr. Med. Chem. 24, 2011-2032 (2017).

19. Kaczanowska, S., Joseph, A. M. \& Davila, E. TLR agonists: our best frenemy in cancer immunotherapy. J. Leukoc. Biol. 93, 847-63 (2013).

20. Huang, S.-W. et al. Imiquimod simultaneously induces autophagy and apoptosis in human basal cell carcinoma cells. Br. J. Dermatol. 163, 310-320 (2010).

21. Yi, J. Y., Jung, Y.-J., Choi, S. S., Hwang, J. \& Chung, E. Autophagy-mediated anti-tumoral activity of imiquimod in Caco-2 cells. Biochem. Biophys. Res. Commun. 386, 455-458 (2009).

22. Uno, K., Kato, K. \& Shimosegawa, T. Novel role of toll-like receptors in Helicobacter pylori - induced gastric malignancy. World J. Gastroenterol. 20, 5244 (2014).

23. Pachathundikandi, S. K., Lind, J., Tegtmeyer, N., El-Omar, E. M. \& Backert, S. Interplay of the Gastric Pathogen Helicobacter pylori with Toll-Like Receptors. Biomed Res. Int. 2015, 1-12 (2015).

24. Smith, S. M. Role of Toll-like receptors in Helicobacter pylori infection and immunity. World J. Gastrointest. Pathophysiol. 5, 133 (2014).

25. Pimentel-Nunes, P. et al. Helicobacter pylori Induces Increased Expression of Toll-Like Receptors and Decreased Toll-Interacting Protein in Gastric Mucosa that Persists Throughout Gastric Carcinogenesis. Helicobacter 18, 22-32 (2013).

26. Wang, X., Xue, L., Yang, Y., Xu, L. \& Zhang, G. TLR9 Promoter Polymorphism Is Associated with Both an Increased Susceptibility to Gastric Carcinoma and Poor Prognosis. PLoS One 8, e65731 (2013).

27. Xu, T. et al. Genetic variations of TLR5 gene interacted with Helicobacter pylori infection among carcinogenesis of gastric cancer. Oncotarget 8, 31016-31022 (2017).

28. Zhao, D. et al. Single-nucleotide polymorphisms in Toll-like receptor genes are associated with the prognosis of gastric cancer and are not associated with Helicobacter pylori infection. Infect. Genet. Evol. 73, 384-389 (2019).

29. Rizzardi, A. E. et al. Quantitative comparison of immunohistochemical staining measured by digital image analysis versus pathologist visual scoring. Diagn. Pathol. 7, 42 (2012).

30. Choudhury, K. R., Yagle, K. J., Swanson, P. E., Krohn, K. A. \& Rajendran, J. G. A Robust Automated Measure of Average Antibody Staining in Immunohistochemistry Images. J. Histochem. Cytochem. 58, 95 (2010).

31. Akbar, S., Jordan, L. B., Purdie, C. A., Thompson, A. M. \& McKenna, S. J. Comparing computer-generated and pathologist-generated tumour segmentations for immunohistochemical scoring of breast tissue microarrays. Br. J. Cancer 113, 1075-1080 (2015).

32. Meyerholz, D. K. \& Beck, A. P. Principles and approaches for reproducible scoring of tissue stains in research. Lab. Investig. 98, 844-855 (2018).

\section{Acknowledgements}

We extend our thanks to Harri Mustonen for his guidance with the statistical methodology, Päivi Peltokangas for her technical assistance with laboratory methods, and Vanessa Fuller for her exceptional English-language revision. This study was financially supported by the Competitive State Research Financing of the Expert Responsibility of Helsinki University Hospital, Helsinki, Finland (C.H.), the Finnish Cancer Foundation (C.H.), 
Finska Läkaresällskapet (C.H. and C.B.), the Sigrid Jusélius Foundation (C.H. and Aa.K.), the K. Albin Johansson Foundation (C.B.), and the Faculty of Medicine, University of Helsinki, Helsinki, Finland (C.B.). The funders had no role in the study design, data collection and analysis, the decision to publish, or in producing the manuscript.

\section{Author Contributions}

Aa.K., C.B., J.H. and C.H. participated in the conceptualizing and design of the work. A.L. and Ar.K. participated in acquisition of patient materials and data curation. Aa.K. and J.H. scored the samples. Aa.K. analysed the results, wrote the original manuscript draft, and prepared the original figures and tables. Each of the authors reviewed the manuscript, the tables, and the figures. C.B. and C.H. equally participated in supervision.

\section{Additional Information}

Supplementary information accompanies this paper at https://doi.org/10.1038/s41598-019-49111-2.

Competing Interests: The authors declare no competing interests.

Publisher's note: Springer Nature remains neutral with regard to jurisdictional claims in published maps and institutional affiliations.

(c) (i) Open Access This article is licensed under a Creative Commons Attribution 4.0 International License, which permits use, sharing, adaptation, distribution and reproduction in any medium or format, as long as you give appropriate credit to the original author(s) and the source, provide a link to the Creative Commons license, and indicate if changes were made. The images or other third party material in this article are included in the article's Creative Commons license, unless indicated otherwise in a credit line to the material. If material is not included in the article's Creative Commons license and your intended use is not permitted by statutory regulation or exceeds the permitted use, you will need to obtain permission directly from the copyright holder. To view a copy of this license, visit http://creativecommons.org/licenses/by/4.0/.

(C) The Author(s) 2019 